traditionally been through paid advertising and campaigning. Promoting traffic safety at workplaces is a new approach.

Objective This project aims to co-operate with different kind of organisations and develop functional operating models in different settings. The employer's motives are concordant with general traffic safety motives and traffic safety is an essential part of the corporate responsibility. The goal is to keep productive labour force safe, able-bodied and avoid unnecessary costs. This action activates workplaces in promoting employees traffic safety. The co-operation with five organisations at Seinäjoki region and the Finnish Traffic Safety Council started on 2015. During the years 2016 and 2017 the project is expanding nationwide. New workplaces are integrated in the project from all Finnish regions and different industries.

Results There have been multiple measures depending on the individual characteristics of the workplace and commuting. During this time inquiries and self-evaluations concerning employees' traffic safety have been used and developed and various training approaches and safety events have been applied to raise awareness about ones' traffic safety. Also a seasonal traffic safety planning tool has been created and there is co-operation with internal communications. This regional co-operation has created new applicable operating models for nationwide traffic safety work.

Conclusions Promoting traffic safety has motivated the occupational safety staff and management of the participating organisations and there are indications that accidents have already decreased. The most important challenge is succeeding in developing such a user friendly approaches that the occupational safety staff can use them as a part of their mundane routines.

\section{DRIVER DISTRACTION IN ROAD TRAFFIC. PRELIMINARY RESULTS OF SAFETY CAMPAIGN}

Petri Jääskeläinen, Pasi Anteroinen. Finnish Road Safety Council

\subsection{6/injuryprev-2016-042156.762}

Background Driver distraction and inattention in road traffic and the resulting accidents have become a world-wide problem. Studies have shown the risk of accident is increased manifold for drivers using a mobile phone while driving.

Methods Before planning of the campaign a total of 1503 persons were interviewed through internet-panel by TNS Gallup Oy. Immediately after the first phase of campaigning, with advertising, a total of 307 persons were interviewed by Dagmar.

Results Four out of ten motorists who had used a mobile phone while driving stated that they had been involved in a dangerous situation in the past two years as a result of their mobile phone use.

Four out of five will answer incoming calls while driving. Two out of three will make calls. One third of all respondents read text messages and social media messages. One quarter writes them while driving.

The distracting effect of mobile phones on driving is well acknowledged.

A three year campaign called "Kun Ajat Aja"- When You Drive, Drive was planned. The campaign aims to increase information on risks of distracted driving, motivate drivers not to text or use social media while driving and support the social norm that drivers should focus on driving.

Preliminary results for the campaign are very positive. Immediately after the first phase of campaigning, 63\% percent of interviewed persons remembered they had seen the campaign.
Conclusions The campaign message was thought relevant and important. From the people surveyed $40 \%$ said the campaign could change their behaviour concerning cell phone use while driving and 38\% said they could now prevent others from using a cell phone while driving.

\section{VISION ZERO - ROAD TRAFFIC EFFECTS FOR SEVERELY INJURED IN A SWEDISH COUNTY}

${ }^{1}$ Astrid Värnild, ${ }^{1,2}$ Matts-Åke Belin, ${ }^{1}$ Per Tillgren. 'Mälardalen University, Sweden; ${ }^{2}$ Transport Administration, Sweden

\subsection{6/injuryprev-2016-042156.763}

Background Vision Zero is a long-term goal, decided by the Swedish Parliament in 1997, which means that no one should be killed or seriously injured as a result of accidents in road traffic and the design and function of the road transport system shall be adapted to meet the requirements that follow from Vision Zero. Based on this decision and strategy several different interventions have been implemented to create a road environment which allows human mistakes. In Sweden state is responsible for roads in rural area and municipalities for roads in urban area. The aim of the study is to evaluate the effects of road safety measures for the group severely injured (ISS $>8$ ) in the county of Västmanland during years 2003-2014 in state and municipal road network.

Methods A longitudinal registry study of a statistical cohort comprised of the county of Västmanland. The study is based on data from emergency hospitals. These data have been combined with data from a national base for road data, NVDB. Descriptive statistics together with trend analysis are applied.

Results Preliminary results for 626 severely injured - 372 injured in municipal roads and 254 in state roads - means that $60 \%$ have been injured on municipal road network. Cyclist and pedestrians dominates the group by $83 \%$. Of cyclists are $72 \% 45$ years and older, while $88 \%$ of pedestrians are 45 years or more. On state roads $70 \%$ of road users are motorists and they are younger than road users in municipal roads. On the municipal road network $69 \%$ were injured in single accidents, while the corresponding proportion of the state road network is $51 \%$.

Conclusions The group severely injured in municipal roads is dominated by unprotected road users mostly older than 45 years, while protected road users are injured in state roads and are younger than injure in municipal roads. These results will be useful for future road safety measures for severely injured.

\section{THE IMPACT OF WORKING MEMORY AND SELECTIVE ATTENTION ON ROAD SAFETY}

${ }^{1,2}$ Cédric Galéra, ${ }^{1,2}$ Cédric Gil-Jardinet, 1,2 Mélanie Née, ${ }^{1,2}$ Rachid Salmi, 1,2 Ludivine Orriols, 1,2 Benjamin Contrand, ${ }^{1,2}$ Emmanuel Lagarde. 'University of Bordeaux, France; ${ }^{2}$ INSERM U897, France

\subsection{6/injuryprev-2016-042156.764}

Background Distracted driving may have serious consequences on road safety. Yet little is known about the impact of some forms of inattention such as executive dysfunctions. In this study we aimed to evaluate the association between working memory, selective attention, and the risk of being responsible for a road crash.

Methods We conducted a responsibility case-control study in an adult emergency department of the Bordeaux university hospital 
in France (2013-2015). Participants were 954 drivers injured in a road crash. The main outcome measure was responsibility for the crash. Covariates were external distraction, working memory, selective attention, alcohol use, psychotropic drug use, and sleep deprivation.

Results A high working memory was associated with responsibility for a traffic crash (odds ratio 1.9, 95\% confidence interval 1.3 to 2.6). Regarding selective attention, the group displaying an hyper focus on stimuli was also associated with responsibility for a traffic crash (odds ratio 1.6, 95\% confidence interval 1.1 to 2.3).

Conclusions Contrary to our expectations unimpaired executive function variables were associated with responsibility for the crash. It is possible that a better level of executive functioning may be linked to a higher focus on internal stimuli thus limiting attention to external and road stimuli.

\section{THE IMPACT OF MIND WANDERING ON ROAD SAFETY}

${ }^{1,2}$ Cédric Galéra, ${ }^{1}$ Cédric Gil-Jardinet, ${ }^{1,2}$ Mélanie Née, 1,2Rachid Salmi, 1,2Ludivine Orriols, 1,2Benjamin Contrand, ${ }^{1,2}$ Emmanuel Lagarde. ' University of Bordeaux, France; ${ }^{2}$ INSERM U897, France

\subsection{6/injuryprev-2016-042156.765}

Background Mind wandering before the crash has been associated with a heightened probability of being responsible for a crash. Yet measurement bias (desirability bias) may explain this association. To progress in the understanding of mind wandering in road safety we sought to assess the relationship between mind wandering trait (a persistent characteristic of the individual) and state (just before the crash) and the risk of being responsible for a road crash.

Methods We conducted a responsibility case-control study in an adult emergency department of the Bordeaux university hospital in France, (2013-2015). Participants were 954 drivers injured in a road crash. Measures were responsibility for the crash, mind wandering (trait/state), external distraction, alcohol use, psychotropic drug use, and sleep deprivation.

Results Intense mind wandering (highly disrupting/distracting content) state was associated with responsibility for a traffic crash (odds ratio 2.3, 95\% confidence interval 1.5 to 3.5). Mind wandering trait was also associated with responsibility for a traffic crash (odds ratio 1.8, 95\% confidence interval 1.3 to 2.5 ).

Conclusions Mind wandering, whether just before the crash or as a general propensity characteristic of the individual, is associated with a higher risk of being responsible for crashes. Mind wandering is a deleterious source of inattention on the road.

\section{IMPLICATIONS OF MARKING REGIONAL AND GLOBAL ROAD SAFETY EVENTS 2014-2015 ON MULTISECTORAL COLLABORATION IN QATAR}

Hassan Al-Thani, Rania Abdelhamid, Monira Mollazehi. Trauma Surgery, Hamad General Hospital, Qatar

\subsection{6/injuryprev-2016-042156.766}

Background Marking of the global and sub-regional road safety events at the national level is one of the recommendations of the Global Plan for the Decade of Action for Road Safety 20112020 to increase the awareness of risk factors and the need for enhanced road traffic injury prevention. Examples of the Global events are the United Nations Global Road Safety Weeks and the
World Remembrance Day for Road Traffic Victims and Subregional road safety event are the Gulf Countries Corporation Traffic Weeks held every year during March.

Objective To examine the implication of marking the global and sub-regional road safety events during 2015 on the road safety awareness agenda in Qatar.

Results The World Remembrance Day for Road Victims was marked in Qatar in the 3rd Sunday of November 2014 by multiple national sectors and demonstrated commitment. Following the event, an in-depth evaluation of the stakeholders needs was done by the awareness section of the Traffic Department and Hamad Injury Prevention Program- Trauma Surgery, Hamad General Hospital and concluded that road safety awareness require a systematic and multi-sectoral collaborative approach. This internal evaluation resulted into a substantial improvement of the collaboration between both sectors, starting from the participation in the $31^{\text {st }}$ Gulf Countries Corporation Traffic Week in March 2015 with several participatory activities by Hamad Injury Prevention Program. Another internal evaluation was conducted following the Gulf Traffic Week to identify progress and needed actions. In May 2015, a more collaborative activity for the $3^{\text {rd }}$ United Nations Global Road Safety Week with emphasised planning using the recommendations of the former events and with involving more sectors such as the Supreme Council of Education and Non-Governmental Organisations. The evaluation of the global event acknowledged that the quality and efficiency of the awareness activities in Qatar was improved by multi-sectoral collaboration and recommended joint planned awareness activities on routine basis.

Conclusions Marking the Global and Sub-regional road safety events emphasised the positive impact of the multi-sectoral collaboration in a systematic way to improve the road safety awareness and guided the national stakeholders in Qatar for future and directed collaborative activities.

\section{Occupational Safety}

\section{Post Tue 2.17}

\section{MUSCULOSKELETAL DISORDERS AND ITS CORRELATES AMONG FARMERS WORKING ON VEGETABLE GREENHOUSE}

Hongyan Yao, Jianjun Liu, Wenjing Zheng. Chinese Centre for Disease Control and Prevention

\subsection{6/injuryprev-2016-042156.767}

Background This study aims to examine the incidence of musculoskeletal disorders (MSDs) among farmers woring on vegetable greenhouse and to identify the potential correlates of musculoskeletal disorders.

Methods A total of 1823 farmers worink on vegetable greenhouse from 15 villages of five main vegetable growing areas in Shouguang city of Shandong province were interviewed using a modified household questionnaire. Chi-square test was performed to assess the incidence of MSDs across farmers with different greenhouses and multivariate logistic regression was performed to explore its risk and protective factors.

Results Among the valid 1780 subjects, 1395 (78.4\%) cases reported that they had the experience of MSDs during the past 12 months. The top four positions with MSDs were low back (62.4\%), knee(s) (41.9\%), neck (22.9\%), and shoulder(s) 